Crônicas de direito internacional ............................................................. Julia Motte-Baumvol e Alice Rocha da Silva

BRAZILIAN TRADE POLICY IN HISTORICAL PERSPECTIVE: CONSTANT FEATURES, ERRATIC BEHAVIOR..11 Paulo Roberto de Almeida

Aspectos GEopolíticos do GAT'T E DA OMC .........................................................28 José Fontoura Costa

A REgulaÇÃo INTERNACIONAL dos SUbSídios AGRÍCOLAS: A CONTEMPORANEIDADE DO PARADIGMA REALISTA PARA A COMPREENSÃO DO SISTEMA DE COMÉRCIO AGRÍCOLA INTERNACIONAL VIGENTE

Natália Fernanda Gomes

ACORDO TRIPS: ONE-SIZE-FITS-ALL?

Tatianna Mello Pereira da Silva

É INTERESSANTE PARA O BRASIL ADERIR AO ACORDO SOBRE COMPRAS GOVERNAMENTAIS DA OMC?

Clarissa Chagas Sanches Monassa e Aubrey de Oliveira Leonelli

A Defesa COMERCIAL E A RESTRIÇÃo dA LIBERALIZAÇÃo E DA INTEGRAÇÃo COMERCIAL PELO AUMENTO DA ALÍQUOTA DE IPI DE VEÍCULOS IMPORTADOS NO BRASIL...................................86

Ricardo Serrano Osorio e Clayton Couto

A COOPERAÇÃo INTERNACIONAL NA DEFESA DA CONCORRÊNCIA

Vinicius Marques de Carvalho e Paulo Burnier da Silveira

Os ACORDOS DE COMÉRCIO PARA ALÉM DAS PREFERÊNCIAS: UMA ANÁLISE DA REGULAMENTAÇÃO SOBRE OS "NOVOS TEMAS" 105

Michelle Ratton Sanchez Badin e Lucas da Silva Tasquetto

INTEGRAÇÃO ECONÔMICA NO MERCOSUL: OPINIÕES CONSULTIVAS E A DEMOCRATIZAÇÃO NO ACESSO AO TRIBUNAL PERMANTE DE REVISÃO 128 Eduardo Biachi Gomes

"Fundos abutres" vs. Estados NaCionais: SObERANiA E ATUAÇÃo do Tribunal INTERNACIONAL do Direito do Mar a partir do Caso da Fragata libertad.. 138 Alexandre Pereira da Silva e Mariana Yante Barrêto Pereira

INVESTIMENTO ESTRANGEIRO: O PADRÃO DE TRATAMENTO JUSTO E EQUITATIVO E O PAPEL DA BOA-FÉ 
Fernando Santos Arenhart

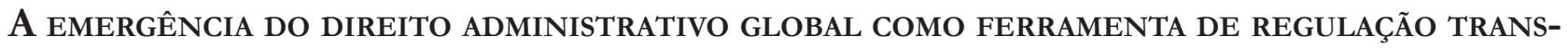
NACIONAL DO INVESTIMENTO ESTRANGEIRO DIRETO .................................................. 171

Andréa Rocha Postiga

Is INVESTMENT ARBITRATION AN APPROPRIATE VENUE FOR ENVIRONMENTAL ISSUES? A LATIN AMERICAN PERSPECTIVE.

Nitish Monebhurrun

A jurisprudência do Superior Tribunal de Justiça e a construção de um Conceito de

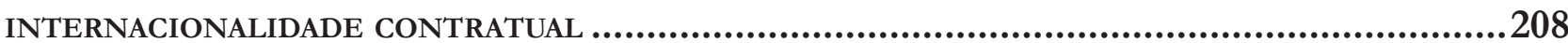

Frederico E. Z. Glitz

IMPACTO E INFLUÊNCIA DOS TRATADOS E CONVENÇÕES INTERNACIONAIS SOBRE A LEI BRASILEIRA DE ARBITRAGEM

Jamile Bergamaschine Mata Diz e Clarissa Correa Neto Ribeiro

A JURISPRUdÊNCIA NORTEAMERICANA E EUROPEIA SOBRE OS ACORDOS HORIZONTAIS E VERTICAIS: SUBSTRATO PARA ANÁLISE DA MATÉRIA NO BRASIL.

Daniel Amin Ferraz 


\section{Geopolitical aspects of the Gatt and the WTO*}

José Fontoura Costa ${ }^{1}$

Professor da Faculdade de Direito de São Paulo (USP) e da Universidade Católica de Santos. Pesquisador produtividade do CNPq.

* Recebido em 14/05/2012

Aprovado em 22/05/2013

\section{Resumo}

$\mathrm{O}$ artigo discute o uso das teorias realistas das Relações Internacionais para compreender a história dos sistemas do GATT e da OMC, bem como um instrumento para estabelecer os possíveis cenários e estratégias da política exterior. Para alcançar tal objetivo, o texto apresenta as mudanças geopolíticas seguidas pelo desenvolvimento institucional do GATTT e da OMC com vistas a identificar os limites e impulsos para o sistema multilateral de comércio devidos a considerações realistas. $\mathrm{O}$ artigo aponta para as preocupações estratégicas e de segurança como fortemente relacionadas com as decisões em matéria de relações econômicas internacionais e seu quadro institucional. Conclui-se que a análise realista e considerações estratégicas são e devem ser feitas para plasmar a política exterior nesse campo. Não há novos dados empíricos apresentados ou discutidos. Não obstante, a construção de um discurso que explica importantes decisões com referência à agenda de segurança dos Estados ajuda a estabelecer um quadro heurístico. Outros trabalhos podem relacionar decisões no campo do Direito internacional econômico a aspectos geopolíticos mediante entrevistas e análise documental, de maneira a auxiliar a compreensão da efetiva dinâmica das tomadas de decisões. A maior parte das discussões sobre as instituições do GATT ou da OMC se restringem a considerações de ordem jurídica ou econômica, como se não houvesse cenários estratégicos em questão. Portanto, o artigo ressalta o papel central de tal campo para estabelecer e implementar metas de política exterior.

Palavras-chave: GATT. OMC. Realismo. Institucionalização. Jurificação. Comércio internacional. Regimes internacionais.

\section{Abstract}

The article discusses the use of realist theories of International Relations to understand the history of the GATT and WTO system as well as an instrument to set possible scenarios and strategies of foreign policy. To reach such objective the text presents the geopolitical changes followed by the institutional development of GATT and WTO in order to identify the constraints and impulses to the multilateral trade system due to realist considerations. The article points strategic and security concerns as strongly linked to decisions regarding international economic relations and its institutional framework. It follows that realistic analysis and strategic considerations are and shall be made to design the foreign policy in this field. There is no new empirical data presented or discussed. However, the construction of a discourse that explains important decisions with reference to the states security 
agenda does help to set a heuristic analysis reference charter. Further works that link decisions in the field of international economic law to geopolitical facts through interviews and documental analysis may help to understand the effective dynamics of decision-making. Most of discussions on GATT or WTO institutions use to be restricted to legal and economic considerations, as if there is no real strategic scenario at stake. Therefore, the article stresses the central role of such field to set and pursue foreign policy aims.

Keywords: GATT. WTO. Realism. Institutionalization. Legalization. International trad. International regimes.

\section{INTRODUÇão}

O surgimento da moderna teoria das relações internacionais é inseparável da reflexão política promovida pelo realismo e é quase impossível lidar com os seus pressupostos teóricos sem esbarrar em hipóteses realista. Assim, a avaliação e a análise de qualquer questão de política internacional ou externa devem passar, pelo menos desde Hans Morgenthau, pela atenção aos cenários traçados conforme os interesses em termos de poder. $^{2}$

Portanto, o presente artigo discute a formação histórica das instituições internacionais que regulamentam o comércio entre os Estados projetando-as sobre os cenários realistas, compreendidos como aqueles em que o poder e as reflexões de caráter estratégico definem ou, pelo menos, limitam as ações políticas. Subjaz, decerto, a questão de se as instituições e regimes internacionais realmente importam ou se os tomadores de decisão sempre os desprezam. Nesse sentido, propõe-se que a necessidade de ter em conta as hipóteses e cenários realistas não elimina a possibilidade de institucionalizar ou jurificar aspectos das relações internacionais: há, entende-se, circunstâncias em que a regulação e o controle do comportamento produzem efeitos e condicionam a tomada de decisões. Em face de ameaças visíveis, porém, os pressupostos realistas tendem a predominar e as decisões estatais, ao fim e ao cabo, não podem ou devem estar desarticuladas das compreensões estratégicas e geopolíticas.

\footnotetext{
${ }^{2}$ MORGENTHAU, Hans J. A política entre as nações. Brasília: EdUnB, IPRI; São Paulo: IOESP, 2003 [1948].
}

Observam-se, para a análise proposta, alguns momentos e movimentos históricos em que as políticas de defesa se articulam com as econômicas. Logo após a Segunda Guerra Mundial, o comércio era visto como um instrumento de garantir a estabilidade política nos Estados Unidos e na Europa Ocidental a partir da manutenção de padrões de vida elevados. Depois disso, as tensões entre capitalismo e comunismo possibilitam o afloramento da cooperação entre países do terceiro mundo, a qual está na raiz de alterações conceituais do Acordo Geral Sobre Tarifas e Comércio (GAT'T) para favorecer os países mais pobres, mais recentes e menos estáveis. Quando caiu o Muro de Berlim, porém, as exigências desses países se debilitam e, por conseguinte, torna-se possível o aparecimento de uma Organização Mundial do Comércio (OMC) contra os interesses dos países em desenvolvimento. Por fim, avalia-se o contexto econômico e geopolítico atual, com ênfase nas incertezas decorrentes de uma profunda redefinição do papel da China nos cenários estratégico e econômico mundiais.

\section{Comércio e segurança}

Se não em Yalta, pelo menos na Cúpula de Potsdam, antes do término da Guerra no Pacífico, as tensões entre EUA, Reino Unido (RU) e União Soviética (URSS) já se mostravam em vivas cores. Não obstante a percepção de que o conflito ideológico e o incremento das tensões entre as duas superpotências eram inevitáveis, tardaria uns poucos anos para se sedimentar. Com efeito, depois do Bloqueio de Berlim, ordenado por Stalin e que durou de junho de 1948 a maio de 1949, as esperanças de um ambiente internacional pacífico e cooperativo foram levadas embora pelos aviões da heróica ponte aérea.

A Segunda Guerra Mundial havia deixado profundos traumas e a relação de seu espocar com a crise econômica e a desorganização da economia mundial levaram a uma reflexão a respeito da necessidade de mecanismos estabilizadores, os quais se concentraram nas instituições de Bretton Woods. ${ }^{3}$ Ao tema do comércio

\footnotetext{
3 JACKSON, John H. The world trading system: law and policy of international economic relations. Cambridge (MA): MIT Press, 1997. JACKSON, John H. "The evolution of the world trading system: the legal and institutional context". In: BETHELEHEM, Daniel et al. (Org.). The Oxford handbook of international trade law. Oxford: Oxford University Press, 2009. LOWENFELD, Andreas F. International economic law. 2. ed. Oxford: Oxford University Press, 2008.
} 
internacional restava um papel menos prioritário.

O GATT nasce exatamente nesse contexto. Entre os 15 países que os Estados Unidos convidaram para negociar reduções tarifárias no final de 1945 estava a União Soviética, ${ }^{4}$ cuja recusa em participar já dava mostras de que a profundidade das discrepâncias ideológicas e das pretensões estratégicas se estendia ao campo econômico. As Propostas para a Expansão do Comércio e Emprego Mundiais, feitas pelos Estados Unidos em novembro de 1945, representavam o resultado de negociações com o Reino Unido desde 1943 e acomodavam os interesses americanos de acesso a mercados aos interesses britânicos de manutenção das preferências imperiais. A política exterior de Roosevelt nunca deixou de buscar erodir o imperialismo britânico e, já na própria Carta do Atlântico, o acesso a recursos naturais e ao comércio surgia como um princípio (Artigo Quatro):

[Os aliados] irão envidar esforços, com o devido respeito às obrigações existentes, para facilitar o gozo por todos os Estados, grandes ou pequenos, vitoriosos ou derrotados, do acesso, em termos equitativos, ao comércio e às matérias-primas do mundo que sejam necessárias para sua prosperidade econômica. 5

Os Estados Unidos, sendo o primeiro a fomentar o multilateralismo comercial, estavam originalmente mais preocupados com o estabelecimento de padrões de não discriminação, especialmente uma cláusula multilateral e automática de nação mais favorecida (NMF), do que com a redução de tarifas, a qual terminou por ser impulsionada pelo Reino Unido, como uma contrapartida à abertura de seu sistema colonial. ${ }^{6}$

É sob tais circunstâncias que o convite americano se estendeu a mais oito países ${ }^{7}$ que, de abril a outubro de 1947,

${ }^{4}$ Estes países foram África do Sul, Austrália, Bélgica, Brasil, Canadá, Checoslováquia, China, Cuba, França, Holanda, Índia, Luxemburgo, Nova Zelândia, Reino Unido e União Soviética. LOWENFELD, Andreas F. International economic law. 2. ed. Oxford: Oxford University Press, 2008. p. 25.

5 A menos que indicado de modo diverso, as traduções são do autor.

6 Reino Unido. GGIE, John G. International regimes, transactions and change: embedded liberalism in the postwar economic order. In: KRASNER, Stephen D. (Org.). International regimes. Ithaca: Cornell University Press, 1983. WINHAM, Gilbert R. "The evaluation of the world trading system: the economic and policy context". In: BETHELEHEM, Daniel et al. (Org.). The Oxford handbook of international trade law. Oxford: Oxford University Press, 2009.

Burma, Ceilão, Chile, Líbano, Noruega, Paquistão, Rodésia do Sul e Síria, que com os Estados Unidos e 14 dos convidados iniciais se converteram em membros originários do GATT. Lista disponível reuniram-se em Genebra. Houve 123 grupos de negociação, que realizaram mais de mil reuniões, o que se chegou a denominar um "circo de três picadeiros". Houve encontros para trabalhar na formulação da Organização Internacional do Comércio, para negociar reduções tarifárias e para estabelecer um código de conduta baseado no princípio da não discriminação e da NMF. Os resultados obtidos nas duas últimas matérias se consolidaram em um documento ${ }^{8}$ : o GATT, aberto à assinatura em 30 de outubro de $1947 .{ }^{9}$

\section{Capitalismo incrustado e novos países}

Politicamente, o objetivo de um mecanismo multilateral de liberalização ia além da mera crença no mercado. A instabilidade interna que marcara as crises políticas que ocorreram no rescaldo da Primeira Guerra Mundial e voltaram a varrer a Europa com a crise anticíclica americana, simbolizada pela quebra da bolsa de Nova Iorque em 1929, era parte importante das preocupações do segundo pós-guerra. Assim, o GATT atenta aos efeitos internos da liberalização e às questões de bem-estar social para evitar qualquer desestabilização econômica que pudesse vir a repercutir na política, já que nas democracias ocidentais a sensibilidade aos temas econômicos é considerável. ${ }^{10}$ Esses elementos de economia e política internas, que superam os limites da análise estrutural em Relações Internacionais, moldam as condições para o aparecimento do que John Ruggie denomina "capitalismo incrustado" (embedded capitalism), noção que ressalta a necessidade de sustentação política do sistema de mercado e, na outra via, a prosperidade gerada pela eficiência como condição da estabilidade política. ${ }^{11}$

em: <http://www.wto.org/english/thewto_e/minist_e/min96_e/ chrono.htm>. Acesso em: 26 jul. 2011.

8 Conforme esclarece John Jackson, o documento foi propositalmente remodelado para que não fosse considerado uma organização e, portanto, ter de ser submetido ao Congresso americano, já que como acordo comercial poderia se beneficiar da autorização de 1945 para o governo negociar. JACKSON, John H. The world trading system: law and policy of international economic relations. Cambridge (MA): MIT Press, 1997.

9 JACKSON, John H. The world trading system: law and policy of international economic relations. Cambridge (MA): MIT Press, 1997. LOWENFELD, Andreas F. International economic law. 2. ed. Oxford: Oxford University Press, 2008.

10 LIPSON, Charles. The transformations of trade: the sources and effects of regime change. In: KRASNER, Stephen D. (Org.) International regimes. Ithaca: Cornell University Press, 1983.

11 RUGGIE, John G. International regimes, transactions and change: embedded liberalism in the postwar economic order. 
Além de acomodar interesses americanos e europeus, o GATT também funcionou como mais uma cunha a forçar a ruptura dos laços coloniais, inclusive mediante o ingresso dos novos países. Logo, porém, o acirramento das tensões com a União Soviética e o início da Guerra Fria proporcionaram um maior alinhamento dos Estados Unidos com o Reino Unido, sem que se abandonasse o apoio à descolonização. Esse cenário atribuiu ao GATT uma nova função: fortalecer os laços dos países capitalistas, incrementando a interdependência e servindo como foro para distender as divergências em matéria comercial e econômica entre americanos e europeus.

A Guerra Fria tomava contornos globais e a disputa por zonas de influência se dava, também, nos territórios colonizados, dado o crescente apoio comunista a movimentos de libertação nacional. Do mesmo modo, as chamadas "guerras por procuração", como a da Coreia (1950 a 1953), a do Vietnã (1957 a 1975), a Irã-Iraque (1980 a 1988) e a Soviético-afegã (1979 a 1989) serviam de campos de confronto para as superpotências que, em face da destruição mútua assegurada, mediam suas forças indiretamente e jamais se confrontaram em campo de batalha. Assim, a preocupação dos Estados Unidos em manter a força da Europa Ocidental se associou à necessidade de pôr atenção nas demandas dos novos países. O crescimento do número de Partes Contratantes do GATT é um dos fatos que indica essa tendência.

O número de Estados na ONU praticamente duplicou até o início dos anos 1960, indo dos 51 membros originários, em 1945, a 104 no final de 1961, passando a crescer em um ritmo menos acelerado até se estabilizar em um patamar de pouco menos de 160 ao longo dos anos 1980. A quase totalidade desses novos membros era composta por países em desenvolvimento, muitos recém saídos da condição colonial.

Assim, o campo para as disputas indiretas pelas zonas de influência aumentou significativamente desde o final da Segunda Guerra Mundial, em que o número de países ainda era relativamente baixo e a repartição feita em Potsdam parecia passível de ser mantida estável. Em face desse novo cenário, a abertura do GAT'T para novos membros não pode ser compreendida como um fenômeno que segue uma racionalidade exclusivamente econômica. A integração de novos países ao comércio internacional é também um instrumento de aproximação política e ideológica.

In: KRASNER, Stephen D. (Org.). International regimes. Ithaca: Cornell University Press, 1983.
Ingressar em um acordo de liberalização comercial demanda pressupostos a mais do que a condição de Estado amante da paz exigida pela ONU. Ainda assim, o GATTT foi bastante ágil em voltar a reduzir a diferença em relação à ONU que, entre 1959 e 1962, saltou de 50 para 70, para a de 57 membros em 1963, no início da Rodada Kennedy, para em seguida manter um patamar abaixo de 60 até 1974. O salto no número de adesões em 1963 se deve, em parte, à existência de um mecanismo preferencial para as antigas colônias, que não necessitaram negociar uma agenda de diminuição tarifária, nos termos do Artigo XXXIII, ${ }^{12}$ mas puderam aceitar as mesmas posições negociadas pela ex-metrópole, nos termos do Artigo XXVI, $4,{ }^{13}$ situação reconhecidamente menos dura do que a enfrentada por outros novos membros. ${ }^{14}$

O tema do desenvolvimento levou algum tempo até chegar ao GATT. As cinco primeiras Rodadas (Genebra, 1947; Annecy, 1949; Torquay, 1950-1951, Genebra, 1955-1956 e Dillon, 1960-1962) trataram principalmente de reduções tarifárias e os eventos mais relevantes foram a entrada da República Federal Alemã, na Rodada Torquay, a sessão de revisão e a adesão japonesa na segunda Rodada de Genebra e a aceitação das Comunidades Europeias na Rodada Dillon. Os ventos, porém, começavam a mudar, com o recrudescimento da Guerra Fria e as crescentes tensões norte-sul.

12 "ADESÕES: Todo Govêrno que não seja Parte Contratante no presente Acôrdo ou todo Govêrno que aja em nome de um território aduaneiro separado que goze de completa autonomia na execução de suas relações comerciais exteriores e nas demais questões tratadas no presente Acôrdo, poderá aderir ao presente Acôrdo em seu próprio nome ou em nome do citado território, nas condições que forem fixadas entre êste Govêrno e as Partes Contratantes." Para este e outros Artigos, texto brasileiro do Decreto 313/1948, Disponível em: <http://www2.mre.gov.br/dai/m_313_1948. htm>. Acesso em: 26 jul. 2011.

13 "ACEITAÇÃO, ENTRADA EM VIGOR E REGISTRO: 4. (...) Ademais, se um dos territórios aduaneiros em cujo nome uma parte contratante aceitou o presente Acôrdo possua ou adquira inteira autonomia na conduta de suas relações comerciais exteriores e nas demais matérias previstas no presente Acôrdo, êsse território será considerado como uma Parte Contratante, como resultado do patrocínio, expresso através de uma declaração que certifique essa circunstância, da Parte Contratante responsável."

${ }^{14}$ BARTON, John $\mathrm{H}$. et al. The evolution of the trade regime: politics, law, and economics of the GATT and the WTO. Princeton: Princeton University Press, 2006. JACKSON, John H. The world trading system: law and policy of international economic relations. Cambridge (MA): MIT Press, 1997. HOEKMAN, Bernard M; KOSTECKI, Michel M. The political economy of the world trade system: the WTO and beyond. 2.ed. Oxford: Oxford University Press, 2001. 
Convertido o Japão em principal aliado dos Estados Unidos no Oriente, em face da expansão do comunismo, o seu ingresso no GATT, em 1955, não deixou de ter seus percalços. Como o país desenvolvia políticas industriais e comerciais agressivas, se não predatórias, fez-se uso abusivo da exceção do Artigo XXXV, ${ }^{15}$ conforme a qual uma Parte Contratante poderia não estender suas obrigações no GATT a um novo aderente por razões políticas. Por ocasião da integração da economia nipônica ao clube que contava, até então, com trinta membros, quinze Estados, “[...] sem qualquer razão política para não estabelecer relações comerciais com o Japão [...] invocaram o Artigo XXXV para negar a aplicar aos produtos japoneses os benefícios de NMF."16

Iniciada em 4 de maio de 1964, em Genebra, a Rodada Kennedy encontra um panorama bastante diverso do das anteriores. Se o Bloqueio de Berlim havia deixado a Guerra Fria às claras, em 1961, a cidade voltaria a ser palco de grandes tensões, com o ultimato de Krushev para a saída das tropas ocidentais e a construção do muro. $\mathrm{O}$ ápice das tensões ainda estava por vir, em outubro de 1962, com a Crise dos Mísseis Cubanos. Ademais, o precedente da fracassada Invasão da Baía dos Porcos, o conflito no Vietnã e a deposição do General Kassem do governo do Iraque, para que o partido Baath, anticomunista, assumisse o poder, são outros eventos que marcaram os anos que antecederam a rodada.

A respeito do amor agridoce dos Estados Unidos em relação à CEE, cuja admissão se discutiu nessa rodada, deve-se ressaltar o predomínio das vantagens políticas da solução do problema da Alemanha combinada com o fortalecimento das democracias ocidentais sobre os eventuais prejuízos em termos de eficiência econômica. Como é bem sabido, “[...] o desvio de comércio piora a alocação internacional de recursos [...], reduz o bem-estar mediante o incremento de custos ou, alternativamente, a redução do ingresso mundial", ${ }^{17}$ mas seus efeitos são menos deletérios

\footnotetext{
15 “1 - Sem prejuízo das disposições da alinea b do parágrafo 5 do artigo XXV ou das obrigações resultantes, para uma parte contratante, das disposições do parágrafo $1^{\circ}$ do artigo XXIX, o presente Acôrdo ou o artigo II do presente Acôrdo não serão aplicáveis entre uma e outra parte contratante:

a) se as duas partes contratantes não entabularem negociações tarifárias entre elas, e

b) se uma ou outra das partes contratantes não consentir nessa aplicação, no momento em que se tornarem partes contratantes."

${ }_{16}$ LOWENFELD, Andreas F. International economic law. 2. ed. Oxford: Oxford University Press, 2008. p. 36.

${ }^{17}$ CHACHOLIADES, Miltiades. International economics. Nova Iorque: McGraw-Hill, 1990. p. 229.
}

em face de tarifas baixas e, de qualquer modo, encaixam-se bem na perspectiva de um liberalismo incrustado. Porém, as intenções americanas de dar mais do que receber estavam arrefecendo e a tônica da Rodada Kennedy seria a reciprocidade. Os Estados Unidos ofereciam benefícios desproporcionais "[...] para induzir as reduções multilaterais de tarifas e incorporar novos Estados no GATT", ${ }^{18} \mathrm{O}$ que só se converteria na exigência de reciprocidade a partir da Rodada Kennedy. ${ }^{19}$

Mas se, por um lado, os fortalecimentos econômicos da Europa e do Japão davam, mediante sua estabilização interna, uma considerável margem de manobra para os Estados Unidos negociarem com maior vigor na seara comercial, por outro lado, a ação concertada dos países em desenvolvimento, politicamente instáveis, tomava corpo. Embora o tratamento especial tenha surgido na revisão do GATTT de 1954 e 1955, a ruptura do consenso liberal ainda não figurava na ordem do dia. Quando foram derrogados temporariamente compromissos de redução tarifária para possibilitar o estabelecimento e fortalecimento da indústria nascente e para fins de equilíbrio da balança de pagamentos (Artigo XVIII, A e B) e autorizados alguns subsídios para exportação de bens industrializados (Artigo XVI), as alterações resultantes realçavam o caráter excepcional e temporário das medidas, como ajustes que iriam, com o aumento do comércio, desaparecendo paulatinamente. ${ }^{20}$ Ainda não se percebia o subdesenvolvimento como estrutural.

\section{SOB A SOMBRA do bILATERALISMO}

A dificuldade de coordenação política entre países em desenvolvimento ocorreu porque após a Segunda Guerra Mundial os novos países, em uma primeira etapa, vincularam sua economia e seu comércio às antigas metrópoles e só depois assumiram como necessária a cooperação entre os países do sul. ${ }^{21}$ Ainda na Rodada

\footnotetext{
18 LIPSON, Charles. The transformations of trade: the sources and effects of regime change. In: KRASNER, Stephen D. (Org.). International regimes. Ithaca: Cornell University Press, 1983. p. 235.

19 BARTON, John $\mathrm{H}$ et al. The evolution of the trade regime: politics, law, and economics of the GATT and the WTO. Princeton: Princeton University Press, 2006. WINHAM, Gilbert R. The evaluation of the world trading system: the economic and policy context. In: BETHELEHEM, Daniel et al. (Org.). The Oxford handbook of international trade law. Oxford: Oxford University Press, 2009.

${ }^{20}$ HUDEC, Robert E. GATT and the developing countries. Columbia Business Law Review, New York, v. 1.992, n. 1, p. 67-80, 1992.

${ }^{21}$ NASSER, Rabih A. A OMC e os paises em desenvolvimento. São Pau-
} lo: Aduaneiras, 2003. 
Kennedy, a disputa por zonas de influência passava pela ajuda internacional aos novos países e as tensões norte-sul ainda se concentravam nas expropriações de investimentos estrangeiros e os padrões de compensação. ${ }^{22}$

As elevadas tensões políticas do período dessa rodada do GATT, assim, atribuíram à disputa por zonas de influência um peso excepcional. Conscientes da possibilidade de obter ganhos desproporcionais a seu poder efetivo e orientados por uma retórica de comunidade de interesses, os novos países demandaram benefícios persistentes. De uma perspectiva realista, portanto, as necessidades estratégicas estadunidenses se refletiram nas negociações comerciais, favorecendo o fortalecimento europeu e a cooptação dos países do Terceiro Mundo.

Ao final das contas, a Rodada Kennedy terminou por enfocar a metodologia e a extensão das concessões tarifárias europeias, com resultados menores do que os esperados, além de estabelecer um código antidumping de pouco alcance e um protocolo, natimorto, sobre a avaliação aduaneira estadunidense. ${ }^{23}$ A participação dos países em desenvolvimento já se fazia sentir e a inclusão da Parte IV do GATT, Comércio e Desenvolvimento, apesar de seu caráter predominantemente exortatório, marca uma clara ruptura no princípio da não discriminação, fazendo surgir uma clara noção de tratamento especial e diferenciado para países em desenvolvimento e admitindo teses do estruturalismo econômico. O GATT já não era um monumento monolítico erigido em honra do liberalismo com bem-estar social dos países industrializados.

As quedas de braços entre Estados Unidos e Comunidades Europeias, as demandas dos países em desenvolvimento e a agressividade das políticas industriais e comerciais asiáticas apontavam para uma ruptura do consenso ideológico e, portanto, para a necessidade da busca de soluções institucionais, que seria a tônica da Rodada Tóquio.

Em termos geopolíticos, o período dessa rodada experimentou uma distensão da Guerra Fria, marcada por negociações entre Estados Unidos e União Soviética, a visita de Nixon à China em 1972, o arrefecimento das guerras por procuração e a unificação do Vietnã

${ }^{22}$ COSTA, José A. F. Direito internacional do investimento estrangeiro. Curitiba: Juruá, 2010. SCHRJIVER, Nico. Sovereignty over natural resources: balancing rights and duties. Cambridge: Cambridge University Press, 1997. SORNARAJAH, M. The international law of foreign investment. 2. ed. Cambridge: Cambridge University Press, 2004.

${ }^{23}$ JACKSON, John H. The world trading system: law and policy of international economic relations. Cambridge (MA): MIT Press, 1997. em 1975. Embora a Revolução Iraniana e a ocupação soviética do Afeganistão viessem a acirrar novamente as tensões, o fato é que a estagnação das economias americana e soviética redirecionou atenções. Nos Estados Unidos, o aumento dos gastos estatais e o esforço militar no Vietnã, combinados com as crises do petróleo de 1973 e 1979, reduziram o ritmo de crescimento e exerceram pressão inflacionária. No bloco soviético, apesar dos lucros petrolíferos, a estagnação econômica, particularmente no setor agrícola, ensejava preocupações. Nos novos países industrializados acelera-se endividamento externo, principalmente a partir do mecanismo que ficou conhecido como a reciclagem dos petrodólares, acompanhado por uma redução do ritmo de crescimento. ${ }^{24}$ A questão do desenvolvimento, acirrada pela escassez de capitais e pela necessidade de tomada de empréstimos privados, passou a ser discutida com maior intensidade na Rodada Tóquio.

Além disso, com a Revolução Iraniana, mitigou-se a percepção de que a prosperidade econômica é, necessariamente, sinônimo de estabilidade política. Como analisa Raymond Aron, a crença de que a estabilidade política é uma função direta do crescimento econômico não se confirmou em países de cultura diferente da ocidental, onde "[...] os protestos contra as dificuldades da existência urbana se misturavam com as saudades do tempo perdido ou com o reflorescer de crenças antigas violadas pela modernização". 25

Assim, o risco de crises políticas capazes de redirecionar as alianças de países periféricos se mostrava particularmente alto. Dadas as causas estruturais e institucionais de tal instabilidade, retomadas por Huntington para explicar a terceira onda de democratização, ${ }^{26}$ reconhecer a diversidade de concepções e as possibilidades de resistência foi a consequência necessária do crescimento de tensões internacionais, de modo que a consideração do desenvolvimentismo como uma ideologia legítima - e não apenas uma tolice engendrada por maus economistas - entrou para a ordem do dia.

\footnotetext{
${ }^{24}$ CHACHOLIADES, Miltiades. International economics. Nova Iorque: McGraw-Hill, 1990.

25 ARON, Raymond. Sobre Clausenvitr. Buenos Aires: Nueva Visión, 2009. p. 113

${ }^{26}$ HUNTINGTON, Samuel P. The Third Wave: democratization in the late Twentieth Century. Norman: University of Oklahoma Press, 1991. Sem embargo, o mesmo autor adota perspectiva pautada por um enfoque culturalista em HUNTINGTON, Samuel P. The clash of civilizations: remaking the world order. Nova Iorque, Touchstone, 1997.
} 
O poder de barganha dos países em desenvolvimento havia sido incrementado pelo maior número de Partes Contratantes e pela ameaça crível de que, sob a liderança soviética, eles sairiam em bloco do GATT para coordenar o comércio internacional desde a Conferência das Nações Unidas para o Comércio e o Desenvolvimento (UNCTAD) ${ }^{27}$ Além disso, em 1974, estabelecem-se os documentos da Nova Ordem Econômica Internacional (Noei), ${ }^{28}$ adotados pela Assembleia Geral das Nações Unidas (AGNU) sem o consentimento dos países industrializados, que se caracterizaram como opositores persistentes, impedindo a formação de costume contra si. ${ }^{29}$

Se em 1968 já havia sido criado o Sistema Geral de Preferências e, em 1970, os waivers, a coesão que redundou nos documentos da Noei também provocou seus efeitos no GATT, de maneira que, entre os resultados da Rodada Tóquio, incluíram-se: (1) a Cláusula de Habilitação, que permite exceções especiais; e (2) algumas decisões que criaram privilégios, como o direito à proteção da indústria nascente e a inclusão em todos os Códigos de regras sobre desenvolvimento. Talvez o mais eloquente exemplo seja a extensão aos países subdesenvolvidos, mediante tratamento de NMF, dos códigos negociados em Tóquio, conforme destacam BARTON et al. ao narrar que, no fechamento da rodada, os funcionários americanos da área comercial não conseguiram apoio do Departamento de Estado para a criação do GATT-Plus, com os novos acordos sem NMF, já que se temia uma "[...] UNCTADização dos países em desenvolvimento num mundo bipolar". ${ }^{30}$

${ }^{27}$ HUDEC, Robert E. GATT and the developing countries. Columbia Business Law Review, New York, v. 1.992, n. 1, p. 67-80, 1992.

28 São os principais documentos que compõem a face jurídica da Noei (ABELLÁN, Victoria. «La cooperación internacional en la solución de problemas de carácter económico y social». In: DIEZ DE VELASCO, Manuel (Org.). Las organizaciones internacionales.

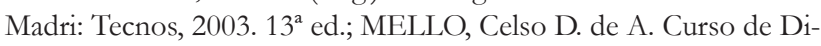
reito internacional público. Rio de Janeiro: Renovar, 2000. v. II.): (1) Declaração para o Estabelecimento de uma Nova Ordem Econômica Internacional - Resolução AGNU 3.201 (S-VI), de maio de 1974; (2) Programa de Ação para o Estabelecimento de uma Nova Ordem Econômica Internacional - Resolução AGNU 3.202 (S-VI), de maio de 1974 e (3) Carta de Direitos e Deveres Econômicos dos Estados - Resolução AGNU 3.281 (XXIX), de dezembro de 1974.

29 BROWNLIE, Ian. The methodological problems of international law and development. Journal of African Law. London, v. 26, n. 1, p. 8-11, 1982. NASSER, Rabih A. A OMC e os paises em desenvolvimento. São Paulo: Aduaneiras, 2003. SCHRJIVER, Nico. Sovereignty over natural resources: balancing rights and duties. Cambridge: Cambridge University Press, 1997.

${ }^{30}$ BARTON, John $\mathrm{H}$. et al. The evolution of the trade regime: politics, law, and economics of the GATT and the WTO. Princeton:
Foram, portanto, significativas as vantagens obtidas pelos países em desenvolvimento estirados à sombra das tensões leste-oeste. Tais benefícios se deveram muito a questões geopolíticas e não estritamente econômicas, o que ressalta a necessidade de um tratamento realista como parâmetro de análise das relações internacionais manifestadas mediante institucionalização em áreas diversas da defesa.

\section{Desenvolvimento, estagnação e (NEO) LIBERALISMO}

Decerto, os anos 1980 viram, em escala internacional, o sucesso do projeto político neoliberal, em especial com os governos Thatcher e Reagan. Além de uma agenda interna de desregulamentação, reduções tarifárias e contínua erosão das conquistas sociais, a qual teve por objetivo devolver à elite econômica parte do poder que esta perdera com as transformações democráticas que reduziram seu controle direto e captura das instâncias estatais ${ }^{31}$, o projeto também tinha uma dimensão internacional, voltado a favorecer a liberalização comercial e a especialização internacional, com divisão do trabalho. Essas finalidades, associadas à contínua afirmação de uma globalização econômica liberal inevitável, marcariam a agenda de negociações da Rodada Uruguai.

Se, em setembro de 1986, o início da Rodada se deu em Punta del Este para simbolizar o compromisso com o desenvolvimento, considerando as dificuldades enfrentadas nos anos 1980 na crise de endividamento, seu final, com a constituição da OMC, em 1994, já divisava um panorama bastante diverso, resultante da queda do comunismo e das preocupações com a globalização.

Embora ainda longe do pico alcançado em 1962, as tensões entre Estados Unidos e União Soviética superavam as do final da Rodada Tóquio. Havia pouco da Revolução Iraniana e havia as guerras Irã-Iraque e Soviético-afegã. Apesar da Glasnost e da Perestroika, os ânimos seguiam acirrados. No entanto, a linha europeia parecia bastante estabilizada, assim como a situação no Extremo Oriente.

No início, era impossível prever a mudança da ordem internacional que se seguiria à queda do Muro de

Princeton University Press, 2006.

31 HARVEY, David. A brief history of neoliberalism. Oxford: Oxford University Press, 2005. 
Berlim e o fim da União Soviética. Os satélites da Europa Oriental, sem a ameaça de intervenções militares, libertaram-se em revoluções que, à exceção de umas poucas escaramuças, foram marcadas pelo suave toque do veludo. A dissolução da Federação Iugoslava , mais sangrenta e longa, já não foi uma guerra por procuração, mas uma guerra civil em que a presença multilateral da ONU buscou mitigar os efeitos maléficos.

A Rússia, reduzida a uma potência regional, perde peso estratégico. Suas tensões geopolíticas se deslocam para a Ásia Central, onde as presenças militares chinesa e estadunidense ensejam a disputa por influência. A Guerra do Golfo ainda seguia a metodologia do chamado posse system, ${ }^{32}$ sem haver uma articulação tipicamente multilateral e, muito menos, orquestrada a partir do Conselho de Segurança da ONU. Discutia-se a existência de uma plena hegemonia americana ou um multilateralismo assimétrico, com predominância estratégica estadunidense.

Se a Agenda de Punta del Este era audaciosa, incluindo temas como serviços, propriedade intelectual, bens agrícolas, têxteis e regras sobre subsídios, muitos dos temas que interessavam aos países em desenvolvimento foram relegados a um segundo plano por ocasião do fechamento em Marraqueche, a 15 de abril de 1994. O relativo equilíbrio inicial entre os interesses dos diferentes grupos de países se havia desfeito, mas não como um resultado das negociações de uma diplomacia parlamentar econômica no seio da Rodada, mas da recomposição de forças em escala global, possibilitando que, pela primeira vez desde as Rodadas Dillon e Kennedy, os países centrais pudessem exercer livremente seu poder. A aliança atlântica, entre Estados Unidos e Comunidades Europeias, agia sem temer qualquer concorrência em face de um Terceiro Mundo desarticulado e sem alternativas.

Pouco menos de um ano depois da Queda do Muro de Berlim, em outubro de 1990, a aliança havia adotado o conceito de single undertaking, de modo que o Acordo Geral sobre Comércio de Serviços (GATS), o Acordo sobre Medidas de Investimento Relacionadas com o Comércio (Trims) e o Acordo sobre Aspectos dos Direitos de Pro-

\footnotetext{
32 No velho oeste americano, o xerife reunia os bons cidadãos para ajudar a perseguir os bandidos, o que recebe o nome de posse. Por conseguinte, se denomina posse system a maneira ad hoc e não institucionalizada de arregimentar aliados para intervenções militares internacionais.
}

priedade Intelectual Relacionadas ao Comércio (Trips) foram consagrados, ao mesmo tempo em que se relegavam as discussões sobre produtos agrícolas e têxteis a um patamar secundário, o que possibilitou uma manobra concertada que não dava opção aos países em desenvolvimento. ${ }^{33}$ A retirada da CE e dos Estados Unidos do GATT forçou a adesão desses Estados à OMC, já que ficar sem garantias de acesso aos mercados americano e europeu seria bem pior que aceitar as novas regras do jogo. ${ }^{34}$

Tal resultado não poderia ocorrer nas condições que marcaram a Guerra Fria. A OMC tem um sentido estratégico bastante diverso daquele do GATT, especialmente à medida que deixa de ser o palco do fortalecimento e da cooptação de aliados do bloco ocidental para se tornar efetivamente universal.

\section{A OMC EM FACE DE NOVOS DESAFIOS}

O sucesso da Rodada Uruguai pode ser explicado a partir do vácuo de poder que se seguiu à queda do sistema soviético, a qual deu maior liberdade aos negociadores comerciais. Não obstante, a utopia de uma Pax Americana duradoura, após o sucesso da transição europeia, desmoronaria a partir do 11 de setembro e do relativo insucesso da reconstrução institucional do Afeganistão e do Iraque. Isso levou a certo grau de dissenso realista, ensejando discussões sobre a redefinição do sistema internacional, o qual parece tender a uma multipolarização. Como aponta Fareed Zakaria, os Estados Unidos são a única superpotência, mas "[...] a multipolaridade não é um fenômeno binário [e] o mundo não continuará unipolar por décadas e, então, repentinamente, tornar-se multipolar do dia para a noite" ${ }^{35}$ e em outras esferas, como a econômica e a cultural, já não existe predomínio americano.

As novas hipóteses variam da unimultipolaridade estratégica de Parag Khanna ${ }^{36}$ à não polaridade enten-

\footnotetext{
33 NASSER, Rabih A. A OMC e os paises em desenvolvimento. São Paulo: Aduaneiras, 2003.

34 BARTON, John $\mathrm{H}$ et al. The evolution of the trade regime: politics, law, and economics of the GATT and the WTO. Princeton: Princeton University Press, 2006.

35 ZAKARIA, Fareed. The future of American power: how America can survive the rise of the rest. Foreign affairs, New York, v. 87. n. 3, p. 43, 2008.

36 KHANNA, Parag. O segundo mundo: impérios e influência na nova ordem global. Rio de Janeiro: Intrínseca, 2008.
} 
dida por Richard Haass como "[...] um mundo dominado não mais por um, dois ou alguns poucos Estados, mas por dezenas de atores exercendo vários tipos de poder", ${ }^{37}$ passando ainda pelo choque de civilizações de Samuel Huntington, ${ }^{38}$ e por modelos mais próximos do realismo clássico, como o da erosão da paz europeia ${ }^{39} \mathrm{e}$ o da ascensão da ameaça chinesa. ${ }^{40}$

Nesses cenários a China protagoniza papéis centrais, inclusive com sua adesão à OMC que, depois de 15 anos do início das tentativas, completou-se em 11 de dezembro de 2001, por decisão da Conferência de Ministros (WT/L/432). ${ }^{41}$ Depois dessa data, o país quadruplicou as exportações e triplicou as importações, passando a representar cerca de $10 \%$ do comércio mundial, sendo que $45 \%$ de suas exportações são destinadas à Ásia e $21 \%$ aos Estados Unidos e à CE. ${ }^{42}$ A longa duração e complexidade do processo se deveram a sentimentos contraditórios em relação à economia chinesa, capaz de oferecer manufaturas de baixo preço, enquanto também representa um mercado gigantesco para produtos e serviços. Por outro lado, a preocupação com a imposição dos critérios do Trips para coibir a pirataria também é significativa. Do ponto de vista da regulação econômica, é melhor incluir a China no sistema da OMC e evitar que esta atue como free rider.

Por outro lado, foi significativa a posição da China no fracasso das negociações da Rodada Doha em 2008, inclusive pelo seu caráter simbólico de marcar uma posição de liderança ao lado da Índia. Isso, entretanto, gera temores de ordem geopolítica em face da possível conversão de capacidade econômica em militar, o que é particularmente sensível quando se considera um país que detém tecnologia nuclear e aeroespacial. Em artigo de 1999, Gerald Segal destaca que a China tem armas nucleares apontadas para os Estados Unidos, rouba segredos militares americanos e faz exercícios de guerra que simulam ataques a posições estadunidenses na Coreia e Japão: não se deve fingir uma aliança estratégica

\footnotetext{
37 HAASS, Richard N. The age of nonpolarity: what will follow U.S. dominance. Foreign affairs, New York, v. 87. n. 3, p. 44, 2008.

38 HUNTINGTON, Samuel P. The clash of civilizations: remaking the world order. Nova Iorque: Touchstone, 1997.

39 KAGAN, Robert. Do paraíso e do poder: os Estados Unidos e a Europa na nova ordem mundial. São Paulo: Rocco, 2003.

40 MEARSHEIMER, John J. The tragedy of great powers politics. Nova Iorque: W.W. Norton, 2001.

${ }^{41}$ Disponível em: <http://www.wto.org/english/thewto_e/ acc_e/completeacc_e.htm\#chn>. Acesso em: 20 jun. 2009.

42 ORGANIZAÇ̃̃O MUNDIAL DO COMÉRCIO. International trade statistics 2008. Genebra: OMC, 2008.
}

inexistente na prática. Ainda assim, a situação "[...] se parece menos com a União Soviética dos anos 1950 do que com o Iraque dos anos 1990: uma ameaça regional a interesses regionais, não um rival ideológico global". ${ }^{43}$

Certamente muito precisas para o momento analisado, mas as preocupações de John Mearsheimer ou Richard Bernstein e Ross Munro, ${ }^{44}$ entre outros, não parecem ser puramente paranoicas. Apesar dos esforços diplomáticos de aproximação da Rússia com Europa e Estados Unidos e da solução de questões territoriais com diversos países da Ásia Central, ${ }^{45}$ a posição americana, depois de lutar três guerras (Japão, Coreia e Vietnã) na região para evitar a consolidação de algum país hegemônico, não tende a se inverter facilmente. A percepção americana da China, como adverte David Lampton, revela-se na visão daquela como vendedora e exportadora, mas não como potencial compradora e investidora, enquanto se subestima o poder intelectual, cultural e simbólico. A ênfase está, então, equivocada, pois são nos âmbitos econômico e intelectual que o poder chinês cresce mais rápido e os americanos estão "[...] jogando o jogo errado, no campo errado, com o time errado". ${ }^{46}$

Essa percepção tríplice do poder (militar, econômico e cultural) não é estranha ao realismo, já que, pelo menos desde Morgenthau, esses elementos fazem parte do cálculo do poder estatal. A China, porém, não é apenas uma potência média regional, apesar da pouca capacidade convencional de extrapolar suas fronteiras e o caráter mais dissuasivo do que ofensivo do seu crescente poder nuclear. No final da primeira década do século XXI, a China continua a crescer e a preocupar. Apesar do aumento de tensões geopolíticas, deve-se atentar às observações de John Ikenberry, que admite a impossibilidade de deter o crescimento do poder chinês e a decadência da hegemonia americana, mas entende que a transição de poder dos Estados Unidos para a China pode ser pacífica e negociada, facilitando a adoção do próprio sistema ocidental para a nova ordem mundial. ${ }^{47}$

\footnotetext{
43 SEGAL, Gerald. Does China matters. Foreign affairs, New York, v. 78 , n. $5,1999$.

${ }^{44}$ BERNSTEIN, Richard; MUNRO, Ross H. The coming conflict with America. Foreign Affairs, New York, v. 76, n. 2, 1997.

45 MEDEIROS, Evan S.; FRAVEL, M. Taylor. China's new diplomacy. Foreign affairs. v. 82, n. 6, 2003.

${ }^{46}$ LAMPTON, David M. The faces of chinese power. Foreign affairs, New York, v. 86, n. 1, 2007.

47 IKENBERRY, G. John. The rise of China and the future of the West: can the liberal system survive? Foreign Affairs, New York, v. 87,
} 
Assim, a integração da China à economia internacional pode ser vista como uma possível estratégia interdependentista de cooptação. Assim, não é razoável, nem factível, pretender evitar o crescimento do poder chinês a partir de restrições comercias e econômicas. Por conseguinte, a adesão da China à OMC é consistente com as percepções realistas, mesmo que seja praticamente certa, senão já consumada, a conversão do Império do Meio em uma potência global.

Além disso, em 2012 e após quase duas décadas de negociações, a Rússia completou o processo de adesão à OMC. É certo que, apesar de uma estrutura política que inspira uma análise cuidadosa e elementos de dirigismo econômico que colocam em dúvida a situação de economia de mercado, espera-se um fortalecimento do comércio internacional a partir do crescimento das importações a serem pagas com o superávit decorrente das vendas internacionais de petróleo e gás.

Do ponto de vista estratégico, o afrouxamento das tensões com os Estados Unidos e a Europa, associado ao marcado retrocesso de conquistas territoriais que colocam a Rússia mais longe das pretensões históricas de controlar a saída do Mar Negro e os Bálcãs, reaviva tensões asiáticas e, particularmente, a vizinhança incômoda da China. É, ainda, uma incógnita qual será o desenvolvimento de suas relações comerciais e econômicas, mas, até o presente, possíveis laços de interdependência econômica parecem mais robustos entre os chineses e seus parceiros ocidentais do que com os russos, cujas principais relações se dão, evidentemente, com os importadores europeus de seus recursos naturais. Assim, faz sentido considerar que tensões estratégicas entre China e Rússia venham a mitigar as possibilidades de cooperação econômica, sobretudo daquela mediada por transferência de tecnologia e investimentos em pesquisa e desenvolvimento.

Houve, portanto, não apenas um considerável aumento do número de Membros da OMC, mas o ingresso de grandes e importantes economias pode ter tornado as negociações mais difíceis e a possibilidade de se conquistar novamente o sucesso das rodadas de negociação parecem mais distantes. Não que um conjunto mais amplo e variado de participantes prejudique a possibilidade de gerar consensos e obter resultados, pois, conforme Barbara Koremenos ${ }^{48}$, quanto mais agudo o proble-

n. 1, 2008.

${ }^{48}$ KOREMENOS, Barbara; LIPSON, Charles; SNIDAL, Duncan. ma distributivo, maior a tendência a abranger âmbitos temáticos mais amplos, o que possibilita transações e concessões cruzadas entre diferentes áreas. Entretanto, a dinâmica de formação de grupos de interesses, homóloga à de coalizões parlamentares, tende a ser pouco estável e com elevados custos para a formação em sistemas nos quais o alinhamento de interesses tende a ser episódico e as tentações de traição constantes, como é

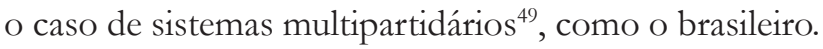
Sem papéis claros de "países em desenvolvimento" e "países desenvolvidos" e na ausência de uma ideologia claramente dominante, tanto a barganha entre grupos contrapostos quanto a formação de novos consensos se torna mais difícil.

A existência de um novo cenário estratégico mundial, no qual várias posições estão pouco definidas, tampouco vem em auxílio das negociações. Postas fora da OMC e, apesar da crescente importância das Nações Unidas e seu Conselho de Segurança, sem um âmbito multilateral de negociação, as tensões geopolíticas podem dificultar a formação de grupos de interesses coesos, bem como de facilitar os planos econômicos de um possível rival militar. Assim, a possibilidade de sucesso das negociações comerciais e econômicas multilaterais parece cada dia mais distante.

\section{A NeCESSIDADE DA PERSPECTIVA REALISTA}

A formação e os primeiros anos do GATT fazem sentido como instrumento de fortalecimento das alianças entre as democracias ocidentais, ao mesmo tempo em que, mediante a cláusula multilateral de NMF, desferem o coup de grâce nas preferências britânicas. Mediante a flexibilidade e a sensibilidade aos desequilíbrios internos, conservava a coesão política dos Estados e reduzia os riscos de conflito. O livre comércio garantia o acesso a matérias-primas estratégicas para o setor de defesa, reduzindo os atritos entre os países da Organização do Tratado do Atlântico Norte - o que foi fortalecido pela criação da Comunidade Europeia do Carvão e do Aço.

Mais adiante, o realismo preveria a adaptação do regime econômico às necessidades estratégicas premen-

The Rational Design of International Istitutions. In: ___ (Org.). The Rational Design of International Institutions. Cambridge: Cambridge University Press, 2004.

49 HEYWOOD, Andrew. Politics. 4. ed. Basingstoke: Palgrave, 2013. 
tes. Com a Guerra Fria em seu ápice, não seria racional que os Estados Unidos recrudescessem as tensões com os países europeus ocidentais e deixassem de favorecer políticas coesivas, inclusive no que dizia respeito à questão alemã, favorecendo a aceitação da CEE no GAT'T. O Japão também foi admitido, de modo a fortalecer os seus vínculos com as políticas ocidentais. Por outro lado, a cooptação dos novos países, todos em desenvolvimento, promovida mediante ajuda financeira associada à assistência técnica e ao auxílio imediato de iniciativas como a Aliança para o Progresso e a Peace Corps, foi estendida ao âmbito comercial, com o parcial sacrifício do multilateralismo.

Da perspectiva realista, portanto, é corroborada a tese de que as instituições pouco importam, senão como um instrumento auxiliar de política exterior. $\mathrm{O}$ multilateralismo não discriminatório já havia servido a seu objetivo original - ajudar a desbaratar o Império Britânico e a fortalecer a presença americana em áreas de tensão e conflito - e devia, portanto, ser flexibilizado para aceitar novos países e acomodar os interesses econômicos. Contrariando a tese do equilíbrio hegemônico, conforme a qual as instituições internacionais são criadas e mantidas apenas como um discurso jurídico que espelha os interesses de uma potência claramente dominante, ${ }^{50}$ a possibilidade de estabelecer consensos em termos de interesses em um âmbito de negociação multilateral pode ser considerada um instrumento da Realpolitik ou, pelo menos, como não contrastante com seus objetivos.

Caído o Muro de Berlim, o predomínio dos Estados Unidos, com a colaboração das CE, possibilitou a difusão de padrões de comércio internacional para os países em transição, sem necessidade de novas concessões aos

\footnotetext{
50 Hipótese surgida em KINDLEBERGER, Charles P. The world in depression: 1929-1939. Berkeley: University of California Press, 1973. Para sua discussão, veja-se também BALDWIN, David A. Neoliberalism, neorealism, and world politics. In: ___ (Org.). Neorealism and neoliberalism: the contemporary debate. Nova Iorque: Columbia University Press, 1993; GONÇALVES, Alcindo; COSTA, José A. F. Governança Global e Regimes Internacionais, São Paulo: Almeidina, 2011; HASENCLEVER, Andreas; MAYER, Peter; RITTBERGER, Volker. Theories of international regimes. Cambridge: Cambridge University Press, 1997; KEOHANE, Robert O. After Hegemony: cooperation and discourse in the world political economy. 2. ed. Princeton: Princeton University Press, 2005; KRASNER, Stephen D. Structural causes and regime consequences: regimes as intervening variables. In KRASNER, Stephen D. (Org.). International Regimes. Ithaca: Cornell University Press, 1983; OYE, Kenneth A. Explaining cooperation under anarchy: hypotheses and strategies. In: (Org.) Cooperation under anarchy. Princeton: Princeton University Press, 1986.
}

em desenvolvimento. A ausência de uma tensão estratégica global, apesar de inúmeras tensões regionais, abriu o espaço de manobra suficiente para que os negociadores comerciais americanos e europeus forçassem o final da Rodada Uruguai, de maneira a favorecer seus interesses.

Atualmente, quando não há uma posição acadêmica única sobre a configuração estrutural do poder, a OMC cumpre o importante papel de fomentar a prosperidade e a interdependência resultantes do incremento dos fluxos comerciais. O caráter multifacetado do poder e a consciência da conversibilidade, em médio prazo, de condições econômicas e culturais em vantagens estratégicas, apontam para a necessidade de negociar com a China para facilitar seu integral ingresso em uma ordem internacional originalmente talhada por artesãos ocidentais, mas cuja abertura - que, pelo menos em parte, decorreu da necessidade americana de expandir geograficamente o alcance do GATT nos anos 1950 e 1960 - pode conduzir a uma redefinição pacífica das posições de poder.

Nada disso, porém, invalida os axiomas realistas e em situações extremas, nas quais as questões estratégicas ganham vulto e os Estados se percebem militarmente ameaçados, a prevalência dos objetivos estratégicos retorna à tona. Nenhum Estado ignora essa realidade e, mesmo que diga o contrário, deve manter a atenção necessária às questões do equilíbrio do poder. Mesmo que se busque um distanciamento desse pessimismo fundamental, conforme o qual os fantasmas do conflito rondam as mais harmoniosas moradas, a realidade é persistente em resistir a uma visão cândida.

Portanto, confundir a análise realista com a adoção pura e simples da hipótese de institucionalização baseada no equilíbrio hegemônico é tratar a corrente fundadora das Relações Internacionais de maneira superficial. Para compreender as conformações institucionais e organizacionais é mister ter em conta as questões geopolíticas e, para tanto, o princípio dos interesses em termos de poder de Hans Morgenthau e a análise estrutural de Kenneth Walz ${ }^{51}$ continuam sendo instrumentos preciosos. Aquele que perde essa dimensão, mesmo que desenvolvendo um discurso sofisticado, corre o risco da inocência idealista. Avaliar os cenários estratégicos e compreender as possíveis ações estatais de maximização

\footnotetext{
51 WALTZ, Kenneth N. Teoria das relaçoes internacionais. Lisboa:
} Gradiva, 2002. 
do poder, portanto, é necessário para traçar um pano de fundo adequado a outros níveis de análise, como os propostos pelo neoliberalismo institucionalista ou pelo próprio construtivismo, já que os limites impostos pela segurança do Estado estarão presentes, pelo menos, por muito tempo.

\section{Conclusão}

A análise proposta no presente artigo sugere, a partir do estudo do desenvolvimento das instituições do GATT e da OMC, que a dimensão geopolítica das relações internacionais é de fundamental importância para a compreensão do sucesso e das transformações pelas quais as Organizações Internacionais passam. Por conseguinte, afirma-se que as tentativas teóricas de reduzir sua dinâmica a quaisquer aspectos que desprezem a importância dos interesses estatais em termos de poder e sua centralidade tendem a produzir leituras enviesadas e insuficientes para explicar os fenômenos internacionais.

No momento em que a escolha de um latino americano para a função de Diretor Geral da OMC, o diplomata brasileiro Roberto Carvalho de Azevêdo, faz soprar novos ventos de esperança, as dificuldades são de proporção hercúlea. Em primeiro lugar, as resistentes crises americana e europeia são um evidente óbice à maior abertura dos mercados e internacionalização de regras e padrões que possam representar qualquer redução da capacidade nacional de propor e implementar políticas sociais. Ao mesmo tempo, a já identificada dificuldade de alinhar interesses e generalizar consensos a partir de posições muito diversas de economias muito relevantes tende a facilitar a ação de filibusteiros e oportunistas, congelando o progresso. Por fim, havendo identificado o provável empastelamento das negociações multilaterais, alguns atores centrais no comércio internacional passaram a adotar estratégias marcadas pela expansão de acordos bilaterais, setoriais e regionais, os quais têm uma abrangência temática mais ampla - aproveitando-se das concessões cruzadas - e são arquitetados para não se chocarem com o sistema multilateral, seja pela incidência da exceção do Artigo XXIV do GAT'T ou pelas preferências garantidas a países em desenvolvimento.

Não obstante as enormes dificuldades já detectadas, a situação geoestratégica também representa limites importantes às possíveis alternativas para a OMC. A recente crise, não completamente resolvida, da Coréia do Norte e as tensões referentes aos possíveis projetos bélicos iranianos não indicam, exatamente, condições de paz e tranquilidade para a Ásia oriental e central, de modo a envolver, exatamente, as duas potências - militares e econômicas - que ingressaram recentemente no sistema multilateral de comércio. Além disso, para quase completar os BRIC, as históricas tensões envolvendo Índia e Paquistão tampouco apontam para uma tranquilidade digna de monges budistas.

Historicamente, a cooperação econômica sempre recua quando há interesses estratégicos em jogo. Os motivos para identificar um tampão econômico no presente, um tempo em que a globalização festejada há pouco mais de dez anos parece estar estagnada ou regredindo, não parecem ser suficientes para gerar uma crença na existência de laços econômicos e sociais tão vigorosos que tornariam os conflitos tão custosos a ponto de garantir a paz.

A euforia neoliberal de um suposto fim da história durou pouco, apesar de haver ajudado a desemperrar algumas negociações que já pareciam fadadas ao fracasso, como a da Convenção das Nações Unidas sobre o Direito do Mar e a própria OMC. Hoje, a ausência de um cenário geopolítico claro, como o que existia no período da Guerra Fria e do equilíbrio pelo terror, inspira tensões, dúvidas e ambiguidades que nem ajudam a levar todos os problemas a uma mesa aberta de negociações, nem a suplantar os interesses e medos pela esperança de bem estar econômico. Nesse sentido, infelizmente, a estagnação da OMC parece receber considerável apoio do âmbito estratégico.

\section{REFERÊNCIAS}

ARON, Raymond. Sobre Clausewitz: Buenos Aires: Nueva Visión, 2009.

BALDWIN, David A. Neoliberalism, neorealism, and world politics. In: (Org.). Neorealism and neoliberalism: the contemporary debate. Nova Iorque: Columbia University Press, 1993.

BARTON, John $H$. et al. The evolution of the trade regime: politics, law, and economics of the GATT and the WTO. Princeton: Princeton University Press, 2006.

BERNSTEIN, Richard; MUNRO, Ross H. The coming conflict with America. Foreign Affairs, New York, v. 76, n. 2, 1997. 
BROWNLIE, Ian. The methodological problems of international law and development. Journal of African Law,London, v. 26, n. 1, p. 8-11, 1982.

CHACHOLIADES, Miltiades. International economics. Nova Iorque: McGraw-Hill, 1990.

COSTA, José A. F. Direito internacional do investimento estrangeiro. Curitiba: Juruá, 2010.

GONÇALVES, Alcindo; COSTA, José A. F. Governança Global e Regimes Internacionais. São Paulo: Almedina, 2011.

HAASS, Richard N. The age of nonpolarity: what will follow U.S. dominance. Foreign affairs, New York, v. 87, n. 3, 2008.

HARVEY, David. A brief history of neoliberalism. Oxford: Oxford University Press, 2005.

HASENCLEVER, Andreas; MAYER, Peter and RITTBERGER, Volker. Theories of international regimes. Cambridge: Cambridge University Press, 1997.

HEYWOOD, Andrew. Politics. 4. ed. Basingstoke: Palgrave, 2013.

HOEKMAN, Bernard M; KOSTECKI, Michel M. The political economy of the world trade system: the WTO and beyond. 2. ed. Oxford: Oxford University Press, 2001.

HUDEC, Robert E. GATT and the developing countries. Columbia Business Law Review, New York, v. 1.992, n. 1, p. 67-80, 1992.

HUNTINGTON, Samuel P. The clash of civilizations: remaking the world order. Nova Iorque: Touchstone, 1997.

HUNTINGTON, Samuel P. The Third Wave: democratization in the late Twentieth Century. University of Oklahoma Press, 1991.

IKENBERRY, G. John. The rise of China and the future of the West: can the liberal system survive? Foreign Affairs, New York, v. 87, n. 1, 2008.

JACKSON, John H. The world trading system: law and policy of international economic relations. Cambridge, MA: MIT Press, 1997.

JACKSON, John H. The evolution of the world trading system: the legal and institutional context. In: BETHELEHEM, Daniel et al.(Org.). The Oxford handbook of international trade law. Oxford: Oxford University Press, 2009.

KAGAN, Robert. Do paraíso e do poder: os Estados Uni- dos e a Europa na nova ordem mundial. São Paulo: Rocco, 2003.

KEOHANE, Robert O. After Hegemony: cooperation and discourse in the world political economy. 2. ed. Princeton: Princeton University Press, 2005.

KHANNA, Parag. O segundo mundo: impérios e influência na nova ordem global. Rio de Janeiro: Intrínseca, 2008.

KINDLEBERGER, Charles P. The world in depression: 1929-1939. Berkeley: University of California Press, 1973.

KOREMENOS, Barbara; LIPSON, Charles; SNIDAL, Duncan. The Rational Design of International Istitutions. In: (Org.). The Rational Design of International Institutions. Cambridge: Cambridge University Press, 2004.

KRASNER, Stephen D. Structural causes and regime consequences: regimes as intervening variables. In: (Org.). International Regimes. Ithaca: Cornell University Press, 1983.

LAMPTON, David M. "The faces of chinese power". Foreign affairs, New York, v. 86, n. 1, 2007.

LIPSON, Charles. The transformations of trade: the sources and effects of regime change. In: KRASNER, Stephen D. (Org.). International regimes. Ithaca: Cornell University Press, 1983.

LOWENFELD, Andreas F. International economic law. 2. ed. Oxford: Oxford University Press, 2008.

MEARSHEIMER, John J. The tragedy of great powers politics. Nova Iorque: W.W. Norton, 2001.

MEDEIROS, Evan S.; FRAVEL, M. Taylor. China's new diplomacy. Foreign affairs, New York, v. 82, n. 6, 2003.

MORGENTHAU, Hans J. A politica entre as nações. Brasília: EdUnB, IPRI; São Paulo: IOESP, 2003 [1948].

NASSER, Rabih A. A OMC e os paises em desenvolvimento. São Paulo: Aduaneiras, 2003.

ORGANIZAÇÃO MUNDIAL DO COMÉRCIO. International trade statistics 2008. Genebra: OMC, 2008.

OYE, Kenneth A. Explaining cooperation under anarchy: hypotheses and strategies. In: (Org.). Cooperation under anarchy. Princeton: Princeton University Press, 1986. 
RUGGIE, John G. International regimes, transactions and change: embedded liberalism in the postwar economic order. In: KRASNER, Stephen D. (Org.). International regimes. Ithaca: Cornell University Press, 1983.

SCHRJIVER, Nico. Sovereignty over natural resources: balancing rights and duties. Cambridge: Cambridge University Press, 1997.

SEGAL, Gerald. Does China matters. Foreign affairs, New York, v. 78, n. 5, 1999.

SORNARAJAH, M. The international law of foreign investment. 2. ed. Cambridge: Cambridge University Press,
2004.

WALTZ, Kenneth N. Teoria das relacões internacionais. Lisboa: Gradiva, 2002

WINHAM, Gilbert R. The evaluation of the world trading system: the economic and policy context. In: BETHELEHEM, Daniel (Org.). The Oxford handbook of international trade law. Oxford: Oxford University Press, 2009.

ZAKARIA, Fareed. The future of American power: how America can survive the rise of the rest. Foreign affairs, New York, v. 87, n. 3, 2008. 
Para publicar na Revista de Direito Internacional, acesse o endereço eletrônico www.rdi.uniceub.br ou www.brazilianjournal.org.

Observe as normas de publicação, para facilitar e agilizar o trabalho de edição. 